\title{
Testing the value of simple arterial blood pressure measurements in a Greek children's hospital"
}

\author{
Konstantinos Tsoumakas ${ }^{1}$, Konstantina Giamaiou ${ }^{1 \#}$, Chara Tzavara ${ }^{2}$, Vasiliki Matziou ${ }^{1}$, \\ Ioannis Elefsiniotis $^{1}$, Evangelia Lagona ${ }^{3}$ \\ ${ }^{1}$ Faculty of Nursing, National and Kapodistrian University of Athens, Athens, Greece \\ ${ }^{2}$ Centre for Health Services Research, Department of Hygiene, Epidemiology and Medical Statistics, Athens University Medical \\ School, Athens, Greece \\ ${ }^{3}$ First University Department of Paediatrics, “Aghia Sophia” Children's Hospital, Athens, Greece \\ Email: " k.giamaiou@,hotmail.gr
}

Received 28 January 2013; revised 28 February 2013; accepted 9 March 2013

Copyright (C) 2013 Konstantinos Tsoumakas et al. This is an open access article distributed under the Creative Commons Attribution License, which permits unrestricted use, distribution, and reproduction in any medium, provided the original work is properly cited.

\begin{abstract}
Arterial hypertension begins in childhood and may continue, without intervention, throughout adulthood with severe health sequelae.The base of timely diagnosis is the systematic blood pressure (BP) measurement. Background: The study aims at revealing the level of parental and community awareness and testing the value of a simple measurement in uncovering children who need further assessment when performing an in-hospital BP screening. Methods: BP was measured in 600 children $(0$ - $17 \mathrm{yr}$, mean age 5.1 $\pm 4.3 \mathrm{yr}$ ) at a Children's hospital. Parents were asked to fill in a specially structured questionnaire. Results: In $47.2 \%$ of the subjects $(40.1 \%$ of them were Greeks and $60.6 \%$ foreigners), BP had never been checked before $(p<0.001)$. Measurements in $25.5 \%$ and $1.6 \%$ of the subjects indicated prehypertension and stage 1 hypertension, respectively. In $55.3 \%$ of these, arterial BP had never been checked before. Surprisingly, a health certificate was issued for school purposes for $\mathbf{8 1 . 2 \%}$ of the schoolchildren of this study, and $75.3 \%$ of the enrolled children were allowed to participate in sports clubs without first checking BP. Moreover, parents demonstrated a low level of alertness with respect to paediatric hypertension. Conclusions: Simple arterial BP measurements can ensure early detection and thus early referral to specialists.
\end{abstract}

Keywords: Children; Hypertension; Blood Pressure Screening; Community Awareness

${ }^{*}$ Conflict of interest: The authors declare no conflict of interest.

\#Corresponding author.

\section{INTRODUCTION}

The prevalence and rate of diagnosis of hypertension in children and adolescents appears to be increasing [1-3]. Despite the increase, hypertension in children, with an estimated prevalence of between $2 \%$ and $5 \%$, is not often diagnosed, even when criteria suggestive of the diagnosis are present in electronic medical records [1-4]. Studies in Greece have suggested that the risk of developing high BP during adolescence can be predicted by BP measurements in childhood $[5,6]$. Consequently, the cornerstone of timely diagnosis is the systematic arterial BP measurement; frequent and correct measurement of $\mathrm{BP}$ is essential $[7,8]$. According to recommendations, the measurement of $\mathrm{BP}$ is considered to be mandatory $[9,10]$. Actually, children aged older than 3 years, who are examined in a medical care setting, should have their BP measured at least once during every health care episode $[9,10]$. As for younger children, BP should be measured specially, for example, when the child presents a morbid neonatal background, known renal disease or familial risk factors [9-12]. Additionally, the routine measurement of BP at school and sport clubs is also recommended [9-15]. However, there is no evidence to date that such recommendations have been incorporated into paediatric clinical practice [11]. The current study aims at identifying whether BP screening is an established practice in Greece (hospitals, schools, sports clubs, and private practices) as well as revealing the level of parental and community awareness, and testing the value of a simple measurement when performing an in-hospital BP screening. Despite paediatric consensus statements and recommendations regarding the importance of measuring $\mathrm{BP}$, health professionals in Greece often neglect the BP measurement in children, whereas parents attribute the fact that they ha- 
ven't taken any action in that direction to lack of information.

\section{METHODS}

\subsection{Participants and Procedure}

A cross sectional study 9 months long was carried out at a University Paediatric Department, at "Aghia Sophia" Children's Hospital, in Athens, Greece. A total of 600 children aged 1 month to 17 years (mean age $5.1 \pm 4.3 \mathrm{yr}$ ) had their BP measured regardless of the reason for admission to hospital. Children's BP was measured and parents answered a specially structured anonymous questionnaire concerning previous BP measurements, their knowledge about paediatric hypertension and the significance of BP screening during childhood. All children's parents or guardians gave informed consent. The study protocol and the including questionnaire were approved by the scientific committee of "Aghia Sophia" Children's Hospital. The independent variables assessed were: sex, child's age, parents' age, parental educational level, parental professional status, nationality and questions concerning parents' views, familial heredity background and the existence of previous BP measurements. Specifically, the study examined the age, the frequency and the place where BP measurements were performed before the study. The study aimed to investigate the reasons why children's BP had not been checked before. In addition, questions related to the examination of BP screening establishment in schools and sports clubs were also included. In order to study whether familial heredity background is associated with the child's BP check during childhood, parents were asked if they were hypertensive and whether their children had any hypertensive relatives or siblings. Parent's views were assessed through questions related to the prevalence of paediatric hypertension, the significance of BP screening during childhood and the necessity of being consistent with BP checks.

\subsection{Anthropometric Measurements and Blood Pressure}

Standing height was measured without shoes to the nearest $0.1 \mathrm{~cm}$ with the use of the clinic stadiometer with children keeping their shoulders in a relaxed position, their arms hanging freely and their head aligned. The line of the observer's sight was parallel with the floor. In infants and toddlers (less than 2 years old) the length was measured twice. Height percentile determined by Greek growth curves for boys and girls aged $0-36$ months and 2 - 18 years respectively [16]. A validated automated electronic device for clinic blood pressure (CBP) measurements was used for the BP measurements $[17,18]$. Correct measurement of BP required use of a cuff appropriate to the child's right arm according to NHBPEP recommendations [9]. BP measurements took place in the patient's room. Special care was taken to ensure that the patient was calm and parents or legal guardians were present during the BP measurements. The first time that the BP was measured in each child, the measurement took place in all four limps in a supine position after a 5 minutes rest [9]. Furthermore, children had avoided stimulant drugs or foods before the BP measurement [9]. In the case of high $\mathrm{BP}$ readings, $\mathrm{BP}$ was measured a second time and the lower reading was evaluated. In infants and toddlers unable to cooperate and easily crying the position wasn't standard but, in case a second BP measurement was needed, the position was the same as in the first measurement, in order to compare the BP readings. The normalcy tables which are published from the NHBPEP were used to evaluate the BP readings [9].

\subsection{Definitions}

The National High Blood Pressure Education Program Working Group on High Blood Pressure in Children and Adolescents (NHBPEP) has presented a classification of hypertension for children of one year of age or older and adolescents and the corresponding systolic BP (SBP) and diastolic BP (DBP) [9]. On the basis of office measurements the 90th, 95th and 99th percentile for gender, age and height are used to classify children and adolescents as normotensive, prehypertensive and stage 1 or stage 2 hypertensive [9]. Normal BP is defined as systolic blood pressure or diastolic blood pressures lower than the 90th percentile for gender, age and height [9]. Hypertension is defined as SBP or DBP that is higher than or equal to 95th percentile for gender, age, and height on at least 3 separate occasions [9]. Stage 1 hypertension is defined as SBP or DBP from 95th percentile to 99th percentile plus $5 \mathrm{mmHg}$ [9]. Stage 2 hypertension is defined as SBP or DBP higher than 99th plus $5 \mathrm{mmHg}$ [9]. Prehypertension is defined as SBP or DBP higher than or equal to 90th percentile but lower than 95th percentile [9]. Adolescents with BP levels higher than or equal to $120 / 80 \mathrm{mmHg}$ considered to be prehypertensive [9]. Ambulatory BP monitoring (ABPM) is usually required for hypertension diagnosis [9-11].

\subsection{Statistical Analysis}

Continuous variables are presented with mean and standard deviation while quantitative variables are presented with absolute and relative frequencies. For the comparison of proportions, chi-square and Fisher's exact tests were used. Student's t-tests were computed for the comparison of mean values between the two groups. Logistic regression analysis in a stepwise method ( $p$ for entry 0.05 , $\mathrm{p}$ for removal 0.10 ) was used in order to find independent factors associated with the variable presented if the 
child's BP had ever been measured. Adjusted odds ratios (OR) with 95\% confidence intervals (95\% CI) were computed from the results of the logistic regression analyses. All p values reported are two-tailed. Statistical significance was set at 0.05 and analyses were conducted using SPSS statistical software (version 17.0).

\section{RESULTS}

Sample consisted of 600 children ( 322 boys and 278 girls). In $52.8 \%$ of the sample arterial BP had been measured in the past. The measurement of arterial BP had been conducted in a public hospital in Greece $(53.5 \%)$, in a private practice $(28.5 \%)$, in a private hospital $(12 \%)$, in a health center $(1.3 \%)$ and in a foreign country $(0.3 \%)$. The majority $(64.5 \%)$ of the group that arterial BP had been measured in the past had only one measurement. The association of previous arterial BP measurement with demographics is shown in Table 1. Children whose arterial $\mathrm{BP}$ had been measured in the past were older and also had older parents. Moreover, children with previous arterial BP measurements had parents with a higher educational level. Lack of previous arterial BP measurements was more frequent in foreigners. Table 2 shows the association of previous BP measurement with parental knowledge concerning paediatric hypertension and the significance of BP screening during childhood. The neglect of previous arterial BP measurement was significantly associated $(\mathrm{p}<0.001)$ with the lack of parental knowledge concerning the abovementioned issues. The association of previous arterial BP measurement with familial heredity background and the demand for a health certificate, either through school enrollment or sports club membership, is shown in Table 3. The existence of a previous arterial BP measurement was more frequent in cases where a history of hypertension in parents or relatives was present $(\mathrm{p}<0.001)$. It was also more frequent in children who had their arterial BP been measured in the past to have been asked for a health certificate during

Table 1. Association of previous BP measurement with demographics.

\begin{tabular}{|c|c|c|c|c|}
\hline & \multirow{2}{*}{ Total } & \multicolumn{2}{|c|}{ Child's arterial BP has previously been measured } & \multirow{3}{*}{$\mathrm{p} \chi^{2}$ test } \\
\hline & & No & Yes & \\
\hline & $\mathrm{N}(\%)$ & $\mathrm{N}(\%)$ & $\mathrm{N}(\%)$ & \\
\hline \multicolumn{5}{|l|}{ Sex } \\
\hline Boys & $322(53.7)$ & $146(51.6)$ & $176(55.5)$ & 0.335 \\
\hline Girls & $278(46.3)$ & $137(48.4)$ & $141(44.5)$ & \\
\hline Age, mean (SD) & $5.1(4.3)$ & $3.5(3.4)$ & $6.6(4.5)$ & $<0.001^{\dagger}$ \\
\hline Age of parent, mean (SD) & $34.5(6.5)$ & $32.4(6.4)$ & $36.4(6)$ & $<0.001^{\dagger}$ \\
\hline \multicolumn{5}{|l|}{ Parental educational level } \\
\hline Elementary school & $92(15.3)$ & $63(22.3)$ & $29(9.1)$ & $<0.001$ \\
\hline High school, lyceum & $328(54.7)$ & $152(53.7)$ & $176(55.5)$ & \\
\hline Technical school, University & $180(30)$ & $68(24)$ & $112(35.3)$ & \\
\hline \multicolumn{5}{|l|}{ Parental professional status } \\
\hline Civil servant & $75(12.5)$ & $27(9.5)$ & $48(15.1)$ & $<0.001$ \\
\hline Private sector employee & $183(30.5)$ & $71(25.1)$ & $112(35.3)$ & \\
\hline Self-employed & $65(10.8)$ & $43(15.2)$ & $22(6.9)$ & \\
\hline Unemployed & $32(5.3)$ & $23(8.1)$ & $9(2.8)$ & \\
\hline Pensioner & $5(0.8)$ & $3(1.1)$ & $2(0.6)$ & \\
\hline Housework & $240(40)$ & $116(41)$ & $124(39.1)$ & \\
\hline \multicolumn{5}{|l|}{ Nationality } \\
\hline Greek & $392(65.3)$ & $157(55.5)$ & $235(74.1)$ & $<0.001$ \\
\hline Foreigners & $208(34.7)$ & $126(44.5)$ & $82(25.9)$ & \\
\hline
\end{tabular}

†Student's t-test. 
Table 2. Association of previous BP measurement with parent's views.

\begin{tabular}{|c|c|c|c|c|}
\hline & \multirow{2}{*}{ Total } & \multicolumn{2}{|c|}{ Child's arterial BP has previously been measured } & \multirow{3}{*}{$\mathrm{p} \chi^{2}$ test } \\
\hline & & No & Yes & \\
\hline & $\mathrm{N}(\%)$ & N (\%) & N (\%) & \\
\hline \multicolumn{5}{|c|}{$\begin{array}{l}\text { Arterial BP frequent measurement is essential } \\
\text { during childhood }\end{array}$} \\
\hline I agree & $462(77)$ & $174(61.5)$ & $288(90.9)$ & $<0.001$ \\
\hline I disagree & $31(5.2)$ & $23(8.1)$ & $8(2.5)$ & \\
\hline I don't know & $107(17.8)$ & $86(30.4)$ & $21(6.6)$ & \\
\hline \multicolumn{5}{|c|}{$\begin{array}{l}\text { Arterial BP measurement in children should be } \\
\text { performed in every medical care setting }\end{array}$} \\
\hline I agree & $363(60.5)$ & $107(37.8)$ & $256(80.8)$ & $<0.001$ \\
\hline I disagree & $95(15.8)$ & $59(20.8)$ & $36(11.4)$ & \\
\hline I don’t know & $142(23.7)$ & $117(41.3)$ & $25(7.9)$ & \\
\hline \multicolumn{5}{|c|}{ Hypertension is a chronic condition in children } \\
\hline I agree & $153(25.5)$ & $30(10.6)$ & $123(38.8)$ & $<0.001$ \\
\hline I disagree & $71(11.8)$ & $30(10.6)$ & $41(12.9)$ & \\
\hline I don't know & $376(62.7)$ & $223(78.8)$ & $153(48.3)$ & \\
\hline
\end{tabular}

Table 3. Association of previous BP measurement with familial heredity background and BP screening in schools and sports clubs.

\begin{tabular}{|c|c|c|c|c|}
\hline & \multirow{2}{*}{ Total } & \multicolumn{2}{|c|}{ Child's arterial BP has previously been measured } & \multirow{3}{*}{$\mathrm{p} \chi^{2}$ test } \\
\hline & & No & Yes & \\
\hline & $\mathrm{N}(\%)$ & $\mathrm{N}(\%)$ & $\mathrm{N}(\%)$ & \\
\hline \multicolumn{5}{|c|}{ Hypertensive siblings } \\
\hline No & $460(97.3)$ & $156(98.1)$ & $304(96.8)$ & $0.557^{\ddagger}$ \\
\hline Yes & $13(2.7)$ & $3(1.9)$ & $10(3.2)$ & \\
\hline \multicolumn{5}{|c|}{ Hypertensive background (one or both parents) } \\
\hline No & $482(80.5)$ & $245(86.9)$ & $237(74.8)$ & $<0.001$ \\
\hline Yes & $117(19.5)$ & $37(13.1)$ & $80(25.2)$ & \\
\hline \multicolumn{5}{|c|}{ Hypertensive relatives } \\
\hline No & $289(48.2)$ & $158(55.8)$ & $131(41.3)$ & $<0.001$ \\
\hline Yes & $311(51.8)$ & $125(44.2)$ & $186(58.7)$ & \\
\hline \multicolumn{5}{|c|}{$\begin{array}{l}\text { Demand for a health certificate during school } \\
\text { enrollment }\end{array}$} \\
\hline No & $277(81.2)$ & $114(95.8)$ & $163(73.4)$ & $<0.001$ \\
\hline Yes & $64(18.8)$ & $5(4.2)$ & $59(26.6)$ & \\
\hline \multicolumn{5}{|c|}{$\begin{array}{l}\text { Demand for a health certificate for the enrollment } \\
\text { in a sports club }\end{array}$} \\
\hline No & $134(75.3)$ & 49 (96.1) & $85(66.9)$ & $<0.001$ \\
\hline Yes & $44(24.7)$ & $2(3.9)$ & $42(33.1)$ & \\
\hline
\end{tabular}

"Fisher's exact test. 
school enrollment or sports club membership $(\mathrm{p}<0.001)$. Multiple logistic regression analysis was conducted in a stepwise method and had as dependent the variable presented if the BP of the child has ever been measured (Table 4). It was found that child age, parental history of hypertension, the demand of a health certificate during school enrollment, parent's views concerning the prevalence of paediatric hypertension and the significance of BP measurement in every medical care setting, were independently associated with the outcome. Specifically, older age, parental history of hypertension and the demand of a health certificate during school enrollment were associated with the increased likelihood of a previous child BP check $(\mathrm{p}<0.001)$. Furthermore, children whose parents pleaded ignorance as to whether hypertension is a common chronic condition in children had reduced possibilities of having measured their arterial BP in the past, compared to those whose parents agreed. The odds for having measured their arterial BP in the past were significantly lower in children whose parents were unaware or disagreed with the statement that arterial BP measurement in children should be performed in every

Table 4. Odds Ratios (OR) and $95 \%$ Confidence Intervals $(95 \% \mathrm{CI})$ derived from multiple logistic regression analysis with dependent the variable presented if the BP of the child has ever been measured.

\begin{tabular}{|c|c|c|}
\hline & OR $(95 \% \mathrm{CI})$ & $\mathrm{p}$ \\
\hline Child age & $1.19(1.10-1.30)$ & $<0.001$ \\
\hline \multicolumn{3}{|c|}{$\begin{array}{l}\text { Hypertensive background (one or } \\
\text { both parents) }\end{array}$} \\
\hline No & $1.00^{*}$ & \\
\hline Yes & $4.29(1.90-9.69)$ & $<0.001$ \\
\hline \multicolumn{3}{|c|}{$\begin{array}{l}\text { Health certificate during school } \\
\text { enrolment }\end{array}$} \\
\hline No & 1.00 & \\
\hline Yes & $6.66(2.33-19.04)$ & $<0.001$ \\
\hline \multicolumn{3}{|c|}{$\begin{array}{l}\text { Hypertension is a chronic condition } \\
\text { in children (Parent statement) }\end{array}$} \\
\hline I agree & 1.00 & \\
\hline I disagree & $0.35(0.12-1.06)$ & 0.064 \\
\hline I don't know & $0.26(0.12-0.57)$ & 0.001 \\
\hline \multicolumn{3}{|c|}{$\begin{array}{l}\text { Arterial BP measurement in children } \\
\text { should be performed in every medical } \\
\text { care setting (Parent statement) }\end{array}$} \\
\hline I agree & 1.00 & \\
\hline I disagree & $0.20(0.09-0.46)$ & $<0.001$ \\
\hline I don't know & $0.12(0.06-0.27)$ & $<0.001$ \\
\hline
\end{tabular}

medical care setting compared to those who agreed with the abovementioned statement. It was found that $71.7 \%$ of the children indicated normal BP, $25.5 \%$ prehypertension and $1.6 \%$ of the children fell into the category of stage 1 hypertension. Additionally, $1.2 \%$ of the children indicated stage 2 hypertension and had already been diagnosed before their admission into hospital. In $55.3 \%$ of children who indicated prehypertension or hypertension BP had never been measured in the past while the corresponding proportion of those with normal BP was $68.1(\mathrm{p}<0.001)$.

\section{DISCUSSION}

According to the NHBPEP recommendations, children aged 3 years or older should have their BP measured when seen at a medical facility [9]. Current guidelines of clinical practice suggest that BP measurement should be carried out at every medical consultation, regardless of the age range of the patient to be assessed [11]. With this study it was found that older children are more likely to have their BP checked than younger children. In the current study, which included only in-hospitalized patients, $40.1 \%$ of Greek children and $60.6 \%$ of the children of immigrants working in Greece hadn't had their BP measured before the study ( $\mathrm{p}<0.001$ ). Although 59.9\% of the Greek children and $39.4 \%$ of the immigrants' children had their BP checked in previous occasions, it is a fact that in $64.5 \%$ of them the BP measurement had taken place once in their lifetime. The study showed that there are more Greek children who have undergone a BP check up in Greece than immigrants' children who live in Greece, which possibly illustrates the lack of concern by the State. It is consequently the obligation of government-owned institutions to ensure equal opportunities by providing not only, for example, vaccinations but also one of the simplest procedures such as the measurement of BP. By this study, it is also confirmed that there is a lack of parental information regarding the necessity of checking $\mathrm{BP}$ in children. In fact, when parents were asked the reason why the BP of their children had never been measured before, they underlined the lack of information as the main reason. In particular, parents who were not aware that hypertension is a chronic condition in children had a $74 \%$ lower probability for their child to undergo a BP check, in comparison with parents who agreed with this fact. Parents who were not aware that arterial BP measurement in children should be performed in every medical care setting had a $88 \%$ lower probability for their child to undergo a BP check, in comparison with those who were aware. What is important is that parents with a hypertensive heredity background demonstrated a greater level of alertness concerning their children's BP check. It seems that there is a need to inform parents, with respect to the significance of routine BP screening, and the conse- 
quences of childhood hypertension in adult life [4-8]. Practices of public hospitals concerning BP screening during childhood in Greece seem to have an impact since in $53 \%$ of the cases BP was measured in a public hospital. Furthermore, private practicing paediatricians in Greece seem to have a significant role since almost $30 \%$ of the children were checked in their private practices. It is also recommended for all children enrolled in school and in sports clubs to be issued a health certificate, for which a BP examination is required [9-12,15]. However, 4 out of 5 schoolchildren have not had their BP checked as required. Logistic regression analysis proved that if BP screening was applied within the school framework, more children would have their BP checked. Even more disappointing is the fact that $75 \%$ of children, who enrolled in a sports club, had not had their BP checked, as required. Apart from the current guidelines, which recommend BP measurements to be performed in all children over 3 years of age when they are seen in a medical setting, measuring $\mathrm{BP}$ in the Emergency Departments (EDs) is considered to have been a valuable opportunity since it is the sole point of contact of children with health services, especially teenagers [19]. Findings indicated that in-hospital arterial BP screening comes up with less false positive results than the one performed in emergency departments. Specifically, studies carried out in several paediatric departments in the USA, Europe and Australia have shown that $\mathrm{BP}$ routine measurements in the EDs are usually neglected by health professionals [19-21]. This is due to the fact that BP measured at triage in the EDs seems to be higher than expected with respect to the prevalence of paediatric hypertension [19-21]. The field of measuring $\mathrm{BP}$ at triage in children with non-urgent problems appears to be quite low since the positive predictive value (PPV) of elevated triage BP in diagnosing true hypertension was $0 \%$ among patients with complete follow up [22]. BP screening actually lacks the criteria of a good screening test and questions the presumed low cost of screening, since follow up of a large number of patients with high BP at triage is not cost effective [23]. Therefore, within the procedures of this study an in-hospital BP screening in paediatric patients was performed, and in this way the limitations of measuring BP in the EDs were overcome. In fact, $2.8 \%$ of children, a total of 17 patients, were found to be hypertensive according to the normalcy tables [9]. Of these, 7 were previously diagnosed and 10 were new cases and therefore referred for further assessment. Obviously, in this setting, which included only in-hospitalized patients, the percent of children found to be hypertensive and the percent of false positive results seem to be lower than the reported at triage in EDs [19-23]. Taking all these into consideration, it is proposed that BP screening be performed in EDs for all children old enough to be able to cooperate (for example older than 8 years). This comes first because it might be their sole point of contact with the healthcare system in Greece and, secondly, because in this way BP screening might become more cost effective. Furthermore, BP screening should be performed in all in-hospitalized patients since false positive results seem to be less than in the frantic EDs [19-23]. Finally, BP check, should be performed in private practices, since family paediatricians in Greece were found to be the second most visited physicians by the younger children. However, simple BP checking does not aim to dispute the necessity of $24 \mathrm{~h}$ ambulatory blood pressure monitoring (ABPM) in the diagnosis and evaluation of paediatric hypertension [9-11,24-25]. It is therefore obvious that the study presented will contribute to the early diagnosis of hypertension and public awareness of BP screening during childhood in Greece.

\section{Limitations}

The study had several limitations. The main restriction was the absence of follow-up concerning the children who indicated hypertension or prehypertension. However, all children who indicated hypertension or prehypertension were referred to a specialist for further assessment. Another limitation was the lack of uniformity of the sample as far as it concerns nationality. Nevertheless, this epidemiological study aimed at finding out whether there is a BP screening on all children residing in Greece or not, and recognising the value of a simple BP measurement within a routine check.

\section{CONCLUSION}

Promoting awareness and simple preventive examinations, as the BP measurement, are constantly overlooked in Greece even by health professionals. Even though the measurement of BP is included in medical examinations for the issuing of a health certificate for the enrollment in school or sports club in Greece, this simple procedure doesn't take place, which furthermore endangers a child's life [4-8]. In-hospital BP screening seems to be of vital importance in the combat with paediatric hypertension. However, more studies are needed to ensure that there is evidence of the incorporation of the recommendations concerning the importance of BP screening during childhood into paediatric clinical practice [9-11]. It is essential to inform parents, with respect to the significance of routine BP screening, and the consequences of childhood hypertension in adult life. It is also necessary that medical personnel should take action with respect to BP measurement and contribute to public awareness. Health professionals are a catalyst for community awareness, screening and prevention with respect to paediatric hy- 
pertension. Simple arterial BP measurements can ensure early detection and thus early referral to specialists.

\section{ACKNOWLEDGEMENTS}

We wish to thank "Aghia Sophia” Children's Hospital in Athens, Greece for giving us the opportunity to accomplish the study. We also thank parents for their willingness to participate in the study.

\section{REFERENCES}

[1] Sorof, J.M., Lai, D., Turner, J., Poffenbarger, T. and Portman, R.J. (2004) Overweight, ethnicity, and the prevalence of hypertension in school-aged children. $P e$ diatrics, 113, 475-482. doi:10.1542/peds.113.3.475

[2] Diz-Dzietham, R., Liu, Y., Bielo, M.V. and Shamsa, F. (2002) High blood pressure trends in children and adolescents in national surveys, 1963 to 2002. Circulation, 116, 1488-1496. doi:10.1161/CIRCULATIONAHA.106.683243

[3] McNiece, K.I., Poffenbarger, T.S., Turner, J.L., Franco, K.D., Sorof, J.M. and Portman, R.J. (2007) Prevalence of hypertension and prehypertension among adolescents. Journal of Pediatrics, 150, 640-644. doi:10.1016/j.jpeds.2007.01.052

[4] Hansen, M.L., Gunn, P.W. and Kaelber, D.C. (2007) Underdiagnosis of hypertension in children and adolescents. JAMA, 298, 874-879.

[5] Kollias, A., Pantsiotou, K., Karpettas, N., Roussias, L. and Stergiou, G.S. (2011) Tracking of BP from childhood to adolescence in a Greek cohort. European Journal of Public Health (on-line).

[6] Kollias, A., Antonodimitrakis, P., Grammatikos, E., Chatziantonakis, N., Grammatikos, E.E. and Stergiou, G.S. (2009) Trends in high blood pressure prevalence in Greek adolescents. Journal of Human Hypertension, 23, 426427. doi:10.1038/jhh.2008.166

[7] Sinaiko, A.R. (1996) Hypertension in children. The New England Journal of Medicine, 335, 1968-1973. doi:10.1056/NEJM199612263352607

[8] Chamontin, B., Amar, J., Barthe, P. and Salvador, M. (1994) Blood pressure measurements and left ventricular mass in young adults with arterial hypertension screened at high school check-up. Journal of Human Hypertension, 8, 357-361.

[9] National High Blood Pressure Education Program Working Group on High Blood Pressure in Children and Adolescents (2004) The forth report on the diagnosis, evaluation, and treatment of high blood pressure in children and adolescents. Pediatrics, 114, 555-576. doi:10.1542/peds.114.2.S2.555

[10] Lurbe, E., Cifkova, R., Cruickshank, J.K., et al. (European Society of Hypertension) (2009) Management of high blood pressure in children and adolescents: Recommendations of the European Society of Hypertension. Journal of Hypertension, 27, 1719-1742. doi:10.1097/HJH.0b013e32832f4f6b

[11] Da Silva, M.A., Rivera, I.R., de Souza, M.G. and Carvalho,
A.C. (2007) Blood pressure measurement in children and adolescents: Guidelines of high blood pressure recommendations and current clinical practice. Arquivos Brasileiros de Cardiologia, 88, 491-495.

[12] Mion Jr., D, Machado, C.A., Gomes, M.A.M., et al. (2004) IV diretrizes brasileiras de hipertensao arterial. Arquivos Brasileiros de Cardiologia, 82, 1-22.

[13] Sorof, J.M., Grafe, R.E., Turner, J.L. and Portman, R.J. (2003) P-557: School-based screening vs. primary care referral of hypertensive children: Relationship to target organ damage. American Journal of Hypertension, 16, 239A-240A. doi:10.1016/S0895-7061(03)00730-1

[14] Moore, W.E., Stephens, A., Wilson, T., Wilson, W. and Eichner, J.E. (2006) Body mass index and blood pressure screening in a rural public school system: The Healthy Kids Project. Preventing Chronic Disease, 3, A114.

[15] Committee on School Health (1981) School health examinations. Pediatrics, 67, 576-577.

[16] Chiotis, D., Tsiftis, G., Hatzisymeon, M., Maniati-Christidi, M. and Dacou-Voutetakis, A. (2003) Height and weight of children of Hellenic origin aged 0 - 18 years (2000-2001): Comparison with data collected during the period 1978-1979. Annals of Clinical Paediatrics University Atheniensis, 50, 136-155.

[17] Stergiou, G.S., Karpettas, N., Atkins, N. and O'Brien, E. (2011) Impact of applying the more stringent validation criteria of the revised European Society of Hypertension International protocol 2010 on earlier validation studies. Blood Pressure Monitoring, 2, 67-73. doi:10.1097/MBP.0b013e32834331e7

[18] Srergiou, G.S., Lourida, P. and Tzamouranis, D. (2010) Replacing the mercury manometer with an oscillometric device in a hypertension clinic: Implications for clinical decision making. Journal of Human Hypertension, 25, 692-698.

[19] Bird, C. and Michie, C. (2008) Measuring blood pressure in children. British Medical Journal, 336, 1321. doi:10.1136/bmj.a150

[20] Silverman, M.A., Walker, A.R., Nicolau, D.D. and Bono, M.J. (2000) The frequency of blood pressure measurements in children in four EDs. American Journal of Emergency Medicine, 18, 784-788. doi:10.1053/ajem.2000.16311

[21] Gilhotra, Y. and Willis, F. (2006) Blood pressure measurements on children in the emergency department. Emergency Medicine Australasia, 18, 148-154. doi:10.1111/j.1742-6723.2006.00824.x

[22] Stewart, J.N., McGillivray, D., Sussman, J. and Foster, B. (2008) The value of routine blood pressure measurement in children presenting to the emergency department with nonurgent problems. Pediatrics, 153, 478-483. doi:10.1016/j.jpeds.2008.03.046

[23] Friedman, A. (2008) Blood pressure screening in children: Do we have this right? Journal of Pediatrics, 153, $452-$ 453. doi:10.1016/j.jpeds.2008.05.014

[24] Karpettas, N., Kollias, A., Vazeou, A. and Stergiou, G.S. (2010) Office, ambulatory and home blood pressure measurement in children and adolescents. Expert Review 
of Cardiovascular Therapy, 8, 1567-1578. doi:10.1586/erc. 10.148

[25] Stergiou, G.S., Nasothimiou, E., Giovas, P., Kapoyiannis, A. and Vazeou, A. (2008) Diagnosis of hypertension in children and adolescents based on home versus ambulatory blood pressure monitoring. Journal of Hypertension, 26, 1556-1562. doi:10.1097/HJH.0b013e328301c411 